\title{
The effect of lattice temperature on surface damage in fused silica optics
}

J. Bude, G. Guss, M. Matthews, M. L. Spaeth

November 12, 2007

Boulder Damage Symposium

Boulder, CO, United States

September 24, 2007 through September 26, 2007 
This document was prepared as an account of work sponsored by an agency of the United States government. Neither the United States government nor Lawrence Livermore National Security, LLC, nor any of their employees makes any warranty, expressed or implied, or assumes any legal liability or responsibility for the accuracy, completeness, or usefulness of any information, apparatus, product, or process disclosed, or represents that its use would not infringe privately owned rights. Reference herein to any specific commercial product, process, or service by trade name, trademark, manufacturer, or otherwise does not necessarily constitute or imply its endorsement, recommendation, or favoring by the United States government or Lawrence Livermore National Security, LLC. The views and opinions of authors expressed herein do not necessarily state or reflect those of the United States government or Lawrence Livermore National Security, LLC, and shall not be used for advertising or product endorsement purposes. 


\title{
The effect of lattice temperature on surface damage in fused silica optics
}

\author{
J. Bude, G. Guss, M. Matthews, and M.L. Spaeth \\ Lawrence Livermore National Laboratory, Mail Stop L-592 \\ 7000 East Avenue, Livermore, CA 94550
}

\begin{abstract}
We examine the effect of lattice temperature on the probability of surface damage initiation for $355 \mathrm{~nm}$, $7 \mathrm{~ns}$ laser pulses for surface temperatures below the melting point to temperatures well above the melting point of fused silica. At sufficiently high surface temperatures, damage thresholds are dramatically reduced. Our results indicate a temperature activated absorption and support the idea of a lattice temperature threshold of surface damage. From these measurements, we estimate the temperature dependent absorption coefficient for intrinsic silica.
\end{abstract}

Key Words: $\mathrm{SiO}_{2}$, laser-induced damage, high temperature absorption

\section{INTRODUCTION}

Little is known about the threshold process which triggers long pulse ( $>20 \mathrm{ps}$ ) laser-induced surface damage in silica optics. In studies of long pulse bulk (defect-free) damage it has been shown that damage in several wide-gap materials including silica is a result of lattice heating induced by multi-photon absorption generated free carriers, not by avalanche ionization ${ }^{[1,2,3]}$. Lattice heating was measured using photo-acoustic techniques and was shown to increase with a power characteristic of multi-photon generation until it reached a critical temperature after which damage occurred. For several crystalline materials, this critical temperature was near the melting point.

Lattice heating has also played an important role in many models for extrinsic damage - damage as a result of defects or absorbing inclusions - although for extrinsic damage, there has never been a direct measurement of lattice temperature just prior to damage as in the bulk damage case. Many of these models employ a temperature threshold which assumes that damage occurs when an absorbing defect reaches a critical temperature ${ }^{[4,5]}$. Typically this is a thermo-mechanical threshold; for example, Stuart et al. have suggested that surface damage in silica occurs when defect absorption is sufficient to melt, boil or fracture the dielectric material ${ }^{[4]}$.

In 2005, Spaeth ${ }^{[6]}$ suggested that damage occurs when the lattice surrounding a precursor (a near-surface absorbing defect or impurity) becomes hot enough to become absorbing itself. Run-away absorption of that small region of the lattice then leads to damage. In this absorption run-away model, lattice temperature plays a direct role by defining a thermo-optical threshold for surface damage, $\mathrm{T}_{\mathrm{X}}$, the temperature above which the intrinsic bulk material becomes strongly absorbing. Surface damage is assumed to occur in two-steps. First, a damage precursor absorbs high fluence light and is heated to $T_{X}$. Once the precursor reaches $T_{X}$, the defect-free silica surrounding it begins to absorb. The higher the lattice temperature, the more the lattice absorbs. This leads to absorption run-away which drives the bulk material to extremely high temperatures and pressures resulting in explosive ejection of material from the surface. Temperatures measured during a damage event for several wide band gap materials exceeded $10,000 \mathrm{~K}{ }^{[7]}$.

Conceptually, the equation for the temperature of the precursor and the material around it exposed to a laser pulse can be written as:

$$
C_{V}(T) \frac{\partial T}{\partial t}=\nabla \bullet(\kappa(T) \nabla T)+I(t)\left(\alpha_{a b s}(r, I, T, \lambda)+\alpha_{I N T}(T, \lambda)\right)
$$


where $I(t)$ is the laser pulse intensity, $\lambda$ is the damage pulse wavelength, $\alpha_{\mathrm{INT}}(T, \lambda)$ is the temperature-activated absorption of intrinsic silica, $\alpha_{a b s}$ is the absorption of the precursor, and $C(T)$ and $\kappa(T)$ are the heat capacity and thermal conductivity of silica respectively. $\alpha_{\mathrm{INT}}(\mathrm{T}, \lambda)$ is a strong function of lattice temperature $\mathrm{T}$, rapidly becoming larger than precursor absorption for $\mathrm{T}>\mathrm{T}_{\mathrm{X}}$.

Although absorption run-away can provide a consistent picture of surface damage, there have been no low pressure measurements of $\alpha_{\mathrm{INT}}(\mathrm{T}, \lambda)$ in silica that would suggest a dramatic increase in absorption near the softening point of silica $(1900 \mathrm{~K})$ as suggested in bulk damage photo-acoustic measurements ${ }^{[1,2]}$. Direct static measurements of high temperature absorption in silica near or above $2000 \mathrm{~K}$ are difficult. Saito et al. have provided careful measurements of silica absorption heated in a furnace up to $1900 \mathrm{~K}$ and for $\lambda<260 \mathrm{~nm}^{[8]}$. Extrapolations of phonon-induced band-gap collapse from this work would require $\mathrm{T}_{\mathrm{X}}>5400 \mathrm{~K}$ for $355 \mathrm{~nm}$ light to directly bridge the optical gap. Dynamic optical reflection measurements during shock heating in silica show a dramatic increase in absorption for $\mathrm{T}>5000 \mathrm{~K}$ and pressures larger than $70 \mathrm{GPa}$, but pressures around an absorbing precursor are expected to be much lower than this ${ }^{[9]}$. At even higher temperatures above $10,000 \mathrm{~K}$, silica is seen to exhibit metallic conductivity.

Inspection of equation (1) above suggests that when the lattice temperature, $\mathrm{T}$, is closer to $\mathrm{T}_{\mathrm{X}}$, less precursor absorption will be required to heat it to $\mathrm{T}_{\mathrm{X}}$ at which point intrinsic absorption turns on. Therefore, the hypothesis of absorption run-away implies that the fluence required to generate damage will be less for damage tests performed at higher lattice temperature. The reduction in threshold will depend on the size of the precursor and the temperature and intensity dependence of its absorption. But, above some lattice temperature, absorption run-away will occur even without an absorbing precursor.

To estimate the magnitude of temperature-activated absorption in silica and to test whether it is large enough to drive absorption run-away, we study the effect of lattice temperature on the probability of surface damage initiation in silica using $355 \mathrm{~nm}, 7 \mathrm{~ns}$ laser pulses. Damage threshold measurements are performed from room temperature to temperatures above the melting point. These measurements allow us to separate the effects of surface conditioning from the temperature-dependent absorption which leads to damage, and to estimate temperature dependent optical absorption in silica for $355 \mathrm{~nm}$ light.

\section{EXPERIMENTAL PROCEDURE}

This experiment required damage testing at temperatures greater than $1900 \mathrm{~K}$ (the softening point of silica). In order to perform damage tests at these temperatures we used a $\mathrm{CO}_{2}(10.6 \mu \mathrm{m})$ laser to heat the surface locally while the bulk of the optic was maintained at room temperature. The $10.6 \mu \mathrm{m}$ heating beam had an $\mathrm{e}^{-2}$ spot diameter of about $1.5 \mathrm{~mm}$ and was focused onto the exit surface of the optic. The surface temperature, $\mathrm{T}_{\mathrm{S}}$, was controlled by adjusting the power of the $10.6 \mu \mathrm{m}$ laser, and the exposure time was $5 \mathrm{~s}$, long enough to reach a steady state surface temperature. To obtain a rough estimate of $\mathrm{T}_{\mathrm{S}}$, we measured the material removed by evaporation at each power level tested and then computed $T_{S}$ using an expression for evaporation rate as a function of temperature, $R_{E}(T)=5 e 9 \exp \left(-3.8 \mathrm{eV} / \mathrm{k}_{\mathrm{B}} \mathrm{T}\right)$ in $\mu \mathrm{m} / \mathrm{s}$, obtained from vapor pressure data. The temperature range spanned by the conditions of this experiment is shown in Fig. 1. Although this is a rather rough way to estimate surface temperature, the results reported below demonstrate important trends with respect to temperature. We are currently working to improve estimates of $T_{S}$ through a series of calibration experiments which combine thermal camera imaging, direct temperature measurements with thermocouples, and modeling.

The damage threshold was measured using a $355 \mathrm{~nm}, 7 \mathrm{~ns}$ laser which was focused through the optic and centered on the region of the exit surface heated by the $10.6 \mu \mathrm{m}$ laser. The $355 \mathrm{~nm}$ beam shape was roughly elliptical, but had an average estimated $\mathrm{e}^{-2}$ diameter of about $100 \mu \mathrm{m}$; in the following, we quote peak fluences assuming a Gaussian beam with an effective $100 \mu \mathrm{m}$ diameter. Here, the damage threshold fluence, $\phi_{\mathrm{TH}}$, is defined as the fluence corresponding to a $50 \%$ damage probability, and was determined as a function of $355 \mathrm{~nm}$ energy by performing about 30 damage tests at energies sufficient to span the range from no damage to nearly $100 \%$ damage. Each site was inspected for damage using bright-field in-situ optical microscopy; when damage occurred, the sites were usually about $25 \mu \mathrm{m}$ in diameter (see Fig. 5). 


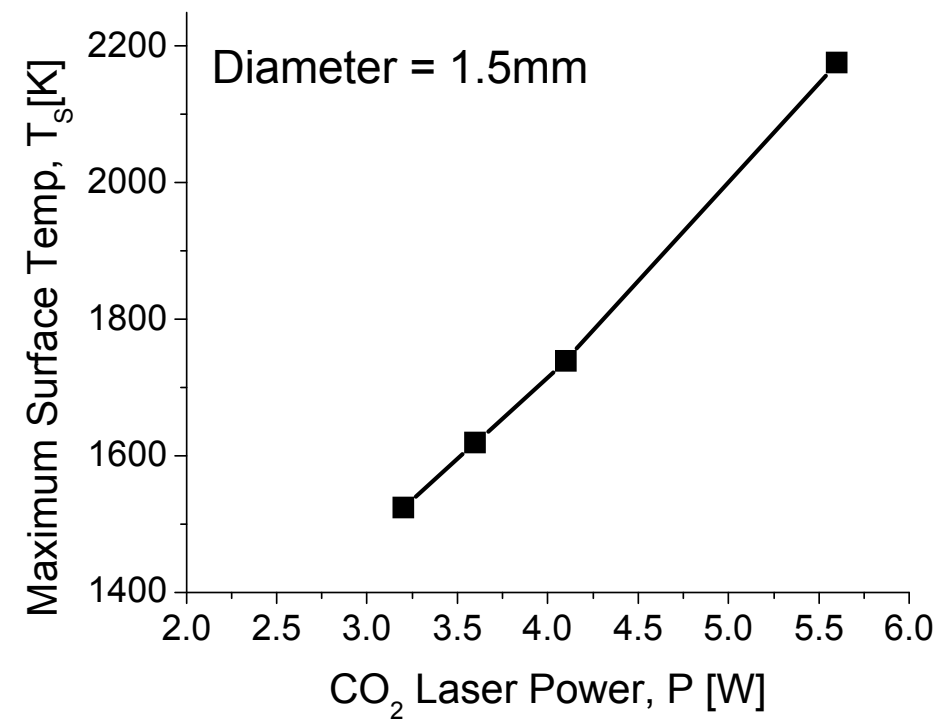

Figure 1: Estimates of surface temperature, $\mathrm{T}_{\mathrm{S}}$, produced by $5 \mathrm{~s} 10.6 \mu \mathrm{m}$ laser exposure.

Surface heating using a $\mathrm{CO}_{2}$ laser has been known to condition the surface, increasing the damage threshold of silica by either removing absorbing precursors or reducing their absorption ${ }^{[10]}$. In order to separate the effect of conditioning from the intrinsic temperature dependence of the damage process, we performed damage tests on surfaces that had been exposed to the same conditioning temperature, $\mathrm{T}_{\mathrm{C}}$. Two damage threshold measurements were performed for each $10.6 \mu \mathrm{m}$ heating pulse power: one with a non-overlapping $355 \mathrm{~nm}$ damage pulse and a $10.6 \mu \mathrm{m}$ heating pulse, and one with overlapping pulses as shown in Fig. 2. In the non-overlapping pulse configuration, the $10.6 \mu \mathrm{m}$ laser heats the surface to $\mathrm{T}_{\mathrm{C}}$; then, the surface is allowed to cool for $20 \mathrm{~s}$ after which the damage pulse is fired. The $50 \%$ damage threshold under these conditions is defined as $\phi_{\mathrm{TH}}\left(\mathrm{T}_{\mathrm{S}}=300 \mathrm{~K}, \mathrm{~T}_{\mathrm{C}}\right)$ - the surface was conditioned to $\mathrm{T}_{\mathrm{C}}$ and then damage tested at $300 \mathrm{~K}$. In the overlapping pulse configuration, the damage pulse is triggered during the last $100 \mathrm{~ms}$ of the heat pulse. Damage testing under these conditions defines the threshold $\phi_{\mathrm{TH}}\left(\mathrm{T}_{\mathrm{S}}=\mathrm{T}_{\mathrm{C}}, \mathrm{T}_{\mathrm{C}}\right)$ - the surface was conditioned to $\mathrm{T}_{\mathrm{C}}$ and then damage tested at the conditioning temperature $\left(\mathrm{T}_{\mathrm{S}}=\mathrm{T}_{\mathrm{C}}\right)$. This process ensures that the precursors have been treated the same way and differences in the damage threshold are independent of the precursor state. The absorption run-away model requires that $\phi_{\mathrm{TH}}\left(\mathrm{T}_{\mathrm{S}}=\mathrm{T}_{\mathrm{C}}, \mathrm{T}_{\mathrm{C}}\right)<\phi_{\mathrm{TH}}\left(\mathrm{T}_{\mathrm{S}}=300 \mathrm{~K}, \mathrm{~T}_{\mathrm{C}}\right)$.

\section{$\mathrm{CO}_{2}$ pulse heats test area}

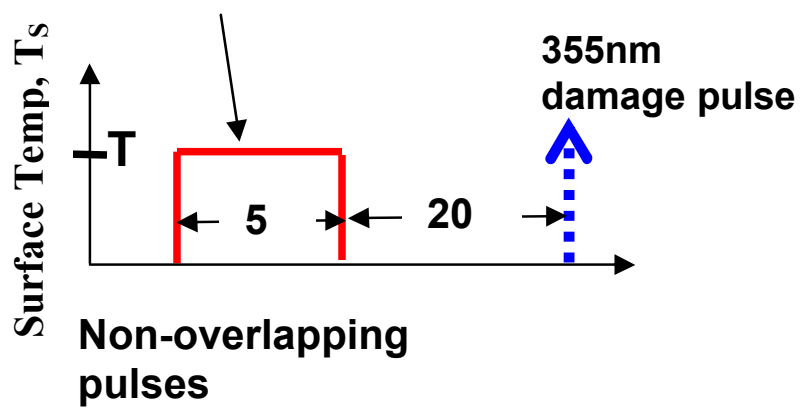

$\mathrm{CO}_{2}$ pulse heats test area

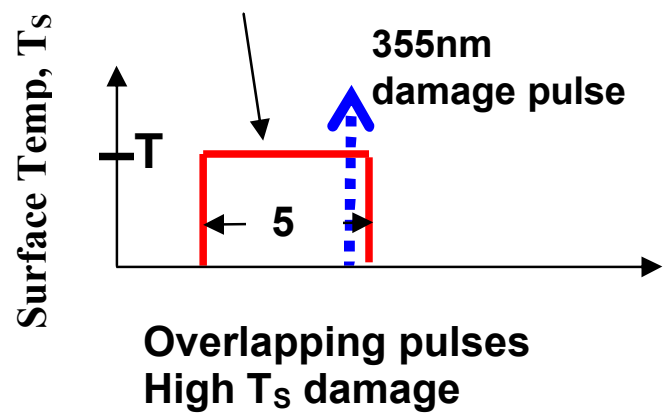

Figure2: Heat pulse and damage pulse synchronization scheme. 


\section{RESULTS}

Figure 3 plots the damage probability tested at room temperature as a function of $355 \mathrm{~nm}$ fluence. The conditioning effect is strong showing an almost four-fold increase in threshold going from $300 \mathrm{~K}$ (no conditioning) to $\mathrm{T}_{\mathrm{C}} \sim 1760 \mathrm{~K}$. Figure 4 shows the $50 \%$ damage threshold, $\phi_{\mathrm{TH}}\left(\mathrm{T}_{\mathrm{S}}=300 \mathrm{~K}, \mathrm{~T}_{\mathrm{C}}\right)$, corresponding to the data of Fig. 3 plotted versus $\mathrm{T}_{\mathrm{C}}$. For the highest conditioning temperature tested (estimated to be about 2200K), there was no damage seen in the conditioned region. This corresponds to an increase in damage threshold of more than a factor of six, and suggests that precursors have been essentially removed from the treated surface region or made non-absorbing.

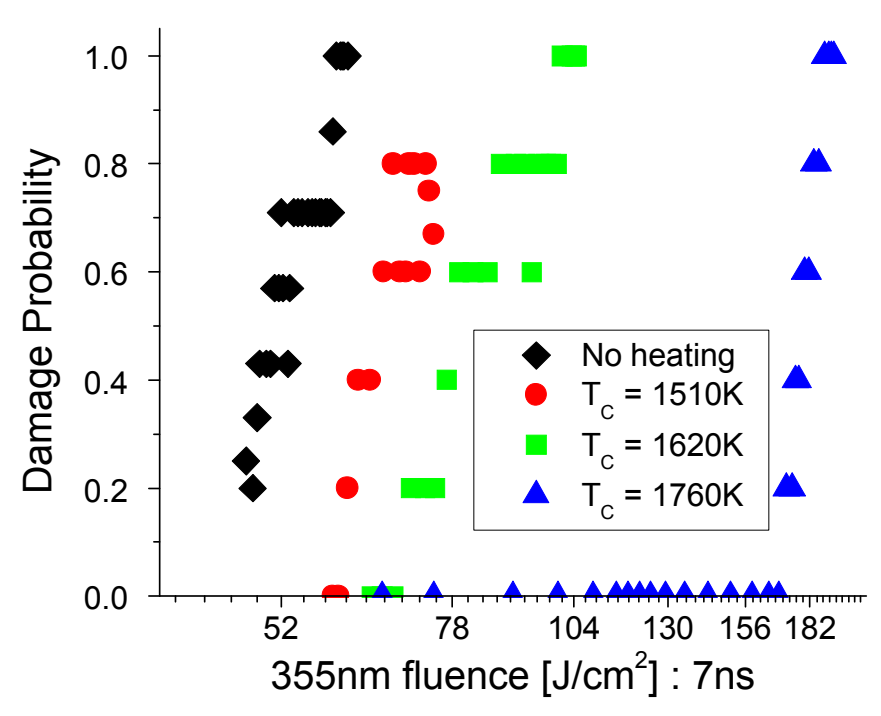

Figure 3: Damage probability as a function of $10.6 \mu \mathrm{m}$ laser conditioning temperature.

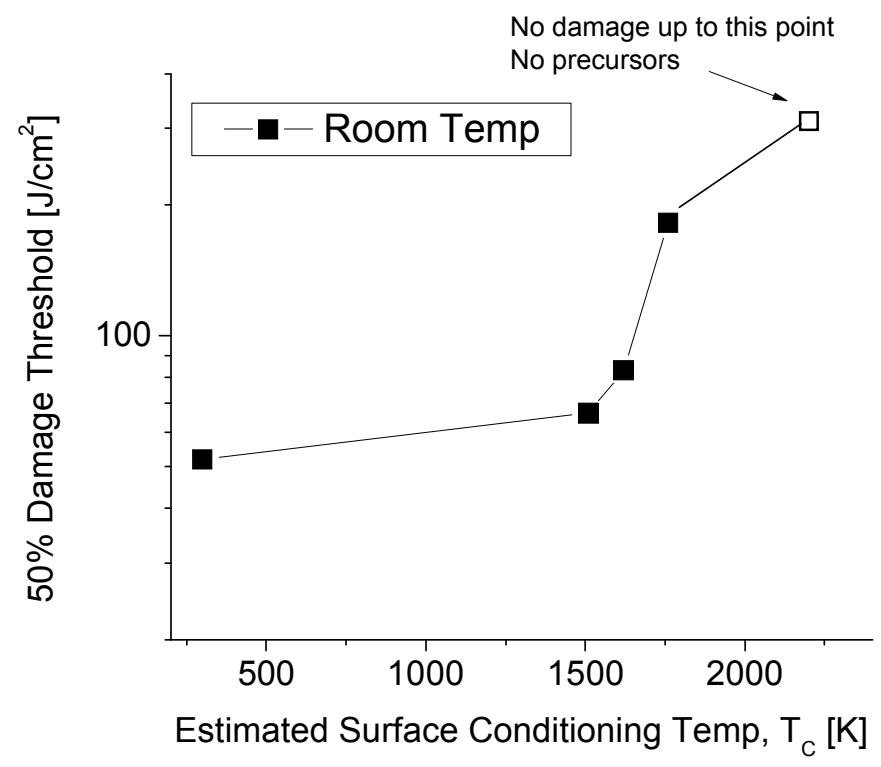

Figure 4: The effects of conditioning on the $50 \%$ damage threshold fluence measured at room temperature, $\phi_{\mathrm{TH}}\left(\mathrm{T}_{\mathrm{S}}=300 \mathrm{~K}, \mathrm{~T}_{\mathrm{C}}\right)$. 
Each point in Fig. 4 reflects the threshold fluence of the surface after conditioning to temperatures up to 2200K. Figure 5 compares the damage thresholds tested at high temperature, $\phi_{\mathrm{TH}}\left(\mathrm{T}_{\mathrm{S}}=\mathrm{T}_{\mathrm{C}}, \mathrm{T}_{\mathrm{C}}\right)$, to the thresholds tested at as shown in room temperature in figure 4 . Both the thresholds tested at room temperature and those tested at high temperature increase with $\mathrm{T}_{\mathrm{C}}$ up to $1760 \mathrm{~K}$. However, when damage tested at high temperatures, the damage threshold is systematically lower than the thresholds in regions tested at room temperature but exposed to the same conditioning temperature $-\phi_{\mathrm{TH}}\left(\mathrm{T}_{\mathrm{S}}=\mathrm{T}_{\mathrm{C}}, \mathrm{T}_{\mathrm{C}}\right)<, \phi_{\mathrm{TH}}\left(\mathrm{T}_{\mathrm{S}}=300 \mathrm{~K}, \mathrm{~T}_{\mathrm{C}}\right)$. In fact, there is almost a $50 \%$ reduction in damage threshold at $\mathrm{T}_{\mathrm{S}}=1760 \mathrm{~K}$ compared to the room temperature threshold. These results support the absorption run-away model - less fluence is required to heat the precursors to $T_{X}$, the temperature where intrinsic absorption in the silica dramatically increases.

The inset microscope images in Fig. 5 show typical damage sites created under the conditions shown. The morphology of damage sites produced at room temperature following conditioning and damage sites produced at high temperatures appear similar to those produced at room temperature with no $10.6 \mu \mathrm{m}$ laser exposure. Consequently, no new damage mechanisms are seen to appear after high temperature conditioning or after damage testing at high $T_{\mathrm{S}}$.

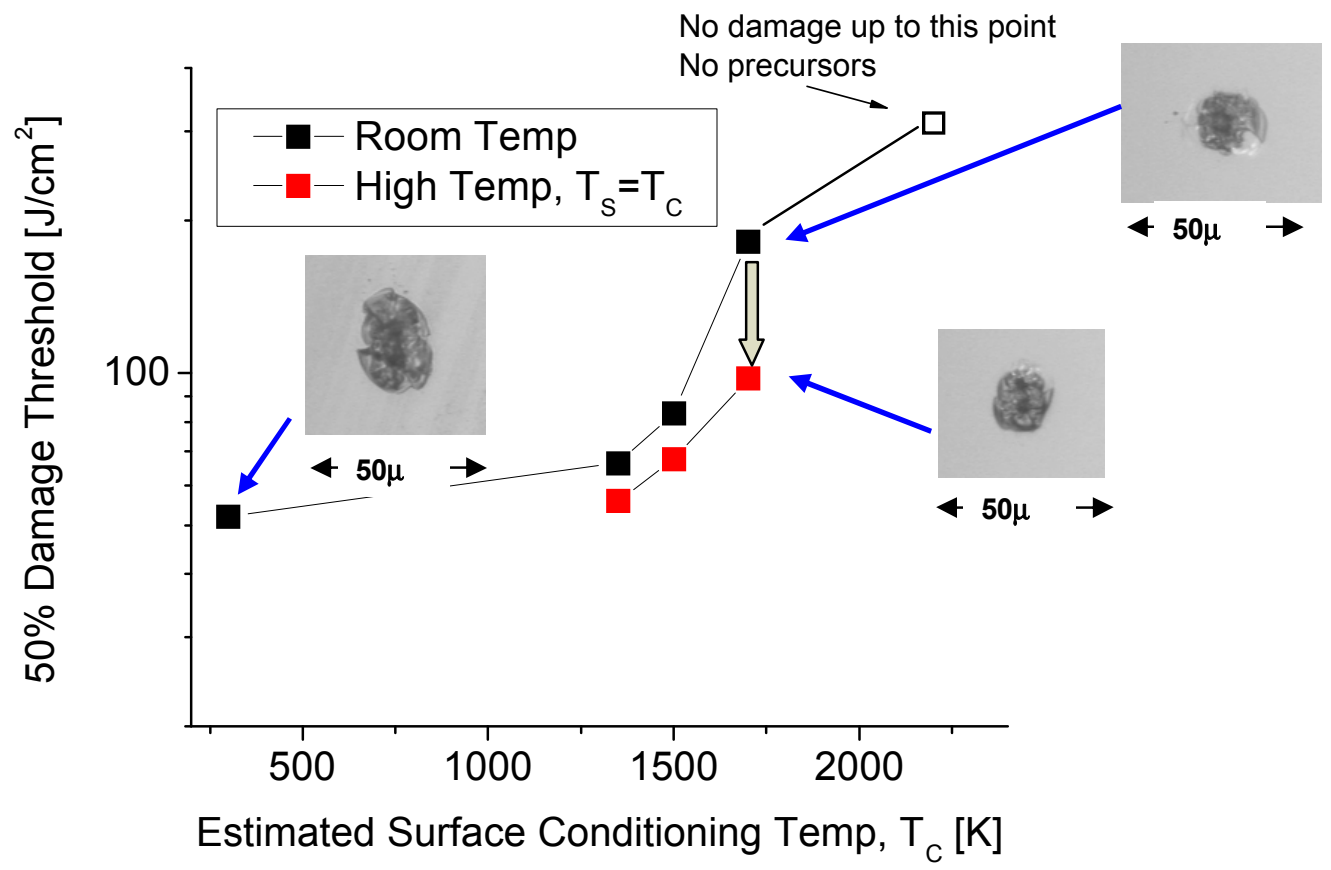

Figure 5: Comparison of damage thresholds and damage site morphology tested at high temperature, $\mathrm{T}_{\mathrm{S}}=\mathrm{T}_{\mathrm{C}}$, to those produced at room temperature.

There is a dramatic change in the behavior of damage sites tested at $2200 \mathrm{~K}$. As shown in Fig. 6, at some point above $1760 \mathrm{~K}$ the threshold no longer increases with $T_{C}$, and at $T_{S} \sim 2200 \mathrm{~K}$, dramatically drops below the un-heated surface threshold. Note that the room temperature threshold conditioned to $2200 \mathrm{~K}$ is more than 10 times higher than the high temperature threshold. Under these conditions, the precursors are either gone or absorb almost no $355 \mathrm{~nm}$ light. At about $2200 \mathrm{~K}$, the silica surface itself begins to absorb $355 \mathrm{~nm}$ light, and temperature-activated absorption in silica near the surface drives a thermal run-away: the higher $T_{S}$ becomes, the more the surface absorbs.

Figure 6 also shows a profile through a damage site created at 2200K and a top-down SEM image of it. The profile clearly shows a narrow damage pit produced by the $355 \mathrm{~nm}$ laser centered within a wider evaporation pit created by the $10 \mu \mathrm{m}$ heating laser. The damage probability curve for these conditions was quite abrupt. Sites exposed to $\mathrm{T}_{\mathrm{C}} \sim 2200 \mathrm{~K}$ but tested at room temperature show only the evaporation pit and did not produce the audible sound of a plasma explosion which accompanied generation of the damage sites produced under the other conditions shown here. The 
damage pit generates a hole at least $7 \mu \mathrm{m}$ deep below the bottom of the evaporation pit. As the $355 \mathrm{~nm}$ pulse passes through the optic it appears to be absorbed by the hot silica just below the evaporation pit, resulting in explosive ejection of material from within the evaporation pit.

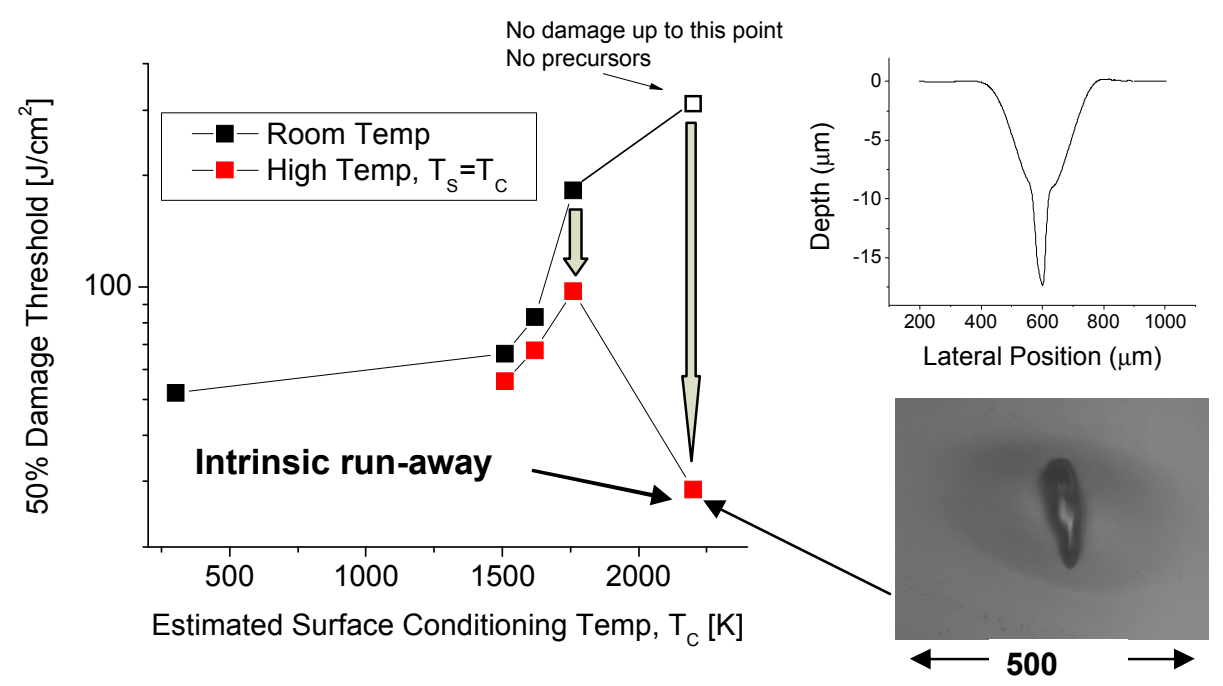

Figure 6: Damage threshold and damage site morphology of a site produced at high temperature (2200K) indicating run-away absorption in the intrinsic silica near the surface.

\section{ANALYSIS AND DISCUSSION}

The results above show evidence of temperature-activated absorption in the intrinsic silica and support the idea that surface damage thresholds are controlled by the fluence required to heat an absorbing precursor to temperatures where intrinsic absorption becomes large. One possible mechanism that could provide a large enough $\alpha_{\mathrm{INT}}(\mathrm{T}, \lambda)$ to drive absorption run-away near $2200 \mathrm{~K}$ is a temperature-induced defect creation model. At high temperatures, the population of defects in nominally defect-free solids exhibits an Arrhenius behavior ${ }^{[11]}$, and consequently absorption by these defects would be strongly temperature activated. Defect generation and absorption models have been used to explain the absorption in Ge-doped optical fibers which leads to the fiber fuse effect (see, for example, ${ }^{[12,13]}$ ). In these models, $\alpha_{\mathrm{INT}}(\mathrm{T}, \lambda)=\alpha_{0}(\lambda) \exp \left(-\mathrm{T}_{0} / \mathrm{T}\right)$ where $\mathrm{kT}_{0}=2.5 \mathrm{eV}$, the Ge-O binding energy. The relevant bond energy for defect creation in silica would be the much higher $\mathrm{Si}-\mathrm{O}$ bond energy, $\mathrm{kT}_{0}=3.5 \mathrm{eV}$, yielding a stronger temperature dependence in silica.

In the following, we have used this form for $\alpha_{\mathrm{INT}}(\mathrm{T}, \lambda)$ to help estimate the magnitude of intrinsic absorption in silica. Equation (1) was solved in bulk with no precursor absorption, and the constant $\alpha_{0}(355 \mathrm{~nm})$ was adjusted to achieve absorption run-away under the conditions measured in Fig. 6. Figure 7 shows simulated bulk temperature, $\mathrm{T}(\mathrm{t})$, for the conditions at and near the condition of run-away $\left(\mathrm{T}_{\mathrm{S}} \sim 2200 \mathrm{~K}, \phi \sim 29 \mathrm{~J} / \mathrm{cm}^{2}\right)$. The plot on the right of Fig. 7 shows the corresponding $\alpha_{\mathrm{INT}}(\mathrm{T}, 355 \mathrm{~nm})$ under the assumptions of the defect model. Here, the absorption at $355 \mathrm{~nm}$ is less than 50 $\mathrm{cm}^{-1}$ near $2200 \mathrm{~K}$, and would be very difficult to measure directly at any temperature below $2000 \mathrm{~K}$. An under-estimate of $\mathrm{T}_{\mathrm{S}}$ at the run-away condition would of course move the curve in Fig. 7 to the right, making absorption at $355 \mathrm{~nm}$ even smaller. From the measurements of Hicks et al., somewhere between 5,000K and 10,000K, silica becomes metalliclike and has an absorptivity greater than $10^{5} \mathrm{~cm}^{-1}{ }^{[9]}$ characteristic of a solid-state plasma. Note that $\mathrm{T}_{\mathrm{X}}$ is not really a model parameter, but simply represents the surface temperature for which intrinsic absorption turns on fast enough to drive absorption run-away and damage. It will be weakly fluence dependent, but under the assumptions and conditions shown here, $\mathrm{T}_{\mathrm{X}} \sim 2200 \mathrm{~K}$.

Point defect generation is only one possible mechanism for temperature-activated absorption. Free carrier absorption of carriers generated by ionized defects or by inter-band absorption through the Urbach tail states ${ }^{[8]}$ may play a role. It has also been suggested that high temperature absorption in optical fibers subject to the fiber fuse effect may be due to 
absorption by $\mathrm{SiO}$ generated by thermal decomposition of silica ${ }^{[13]}$. More work is needed to confirm which mechanism dominates in the temperature range of interest.
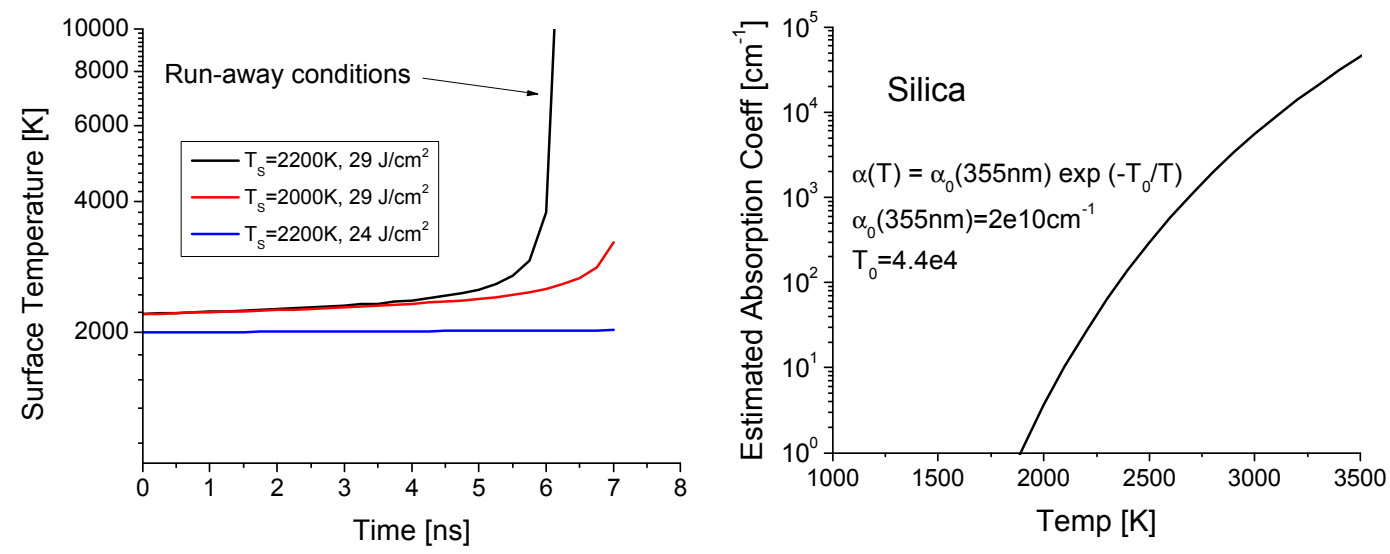

Figure 7: Simulated surface temperature during absorption run-away and estimated intrinsic absorption coefficient to achieve runaway assuming a temperature-activated defect generation and absorption model.

\section{CONCLUSIONS}

We have experimentally demonstrated high temperature run-away absorption on silica surfaces. After separating the effects of conditioning from the temperature dependence of damage initiation, we found that the surface damage threshold for $T_{S}>1500 \mathrm{~K}$ is reduced compared to its room temperature value. The higher the surface temperature becomes, the larger the reduction in threshold. These results support a threshold model based on absorption run-away. Further work is needed to more accurately estimate the surface temperature, but the trends versus temperature are clear. Temperature-activated defect generation is one possible explanation for the behavior seen here, but more work is needed to confidently identify the mechanisms responsible for high temperature absorption. Finally, this work can form the basis for more sophisticated models of energy deposition including material motion and the behavior of precursor absorption capable of an accurate description of the dynamics of a damage event.

\section{ACKNOWLEDGEMENTS}

The authors would like to thank Mike Feit and Ken Manes for insightful discussions. This work was performed under the auspices of the U.S. Department of Energy by Lawrence Livermore National Laboratory under Contract DE-AC52$07 N A 27344$.

\section{REFERENCES}

1. X. A. Shen et al., "Laser Heating of Free Electrons in Wide-gap Optical Materials at 1064nm," Phys. Rev. Lett., 62, $2711,1989$.

2. P. Kelly, "Laser-induced material modifications," Optical Engineering, 28, p.1023, 1989.

3. S. C. Jones et al., "Prebreakdown energy absorption from intense laser pulses at 532nm in NaCal," 37, p. 755, 1988.

4. B.C. Stuart et al., "Nanosecond-to-femtosecond laser-induced breakdown in dielectrics," Phys. Rev. B. Vol. 53, 4, 1996.

5. M.D. Feit and A.M. Rubenchik, "Implications of nanoabsorber initiators for damage probability curves, pulselength scaling and laser conditioning," Proc. of SPIE Vol. 5273, p. 74, 2004.

6. M.L. Spaeth, private communication.

7. C. Carr et al., "Localized Dynamics during Laser-Induced Damage in Optical Materials," Phys. Rev. Lett., 92, $087401,2004$.

8. K. Saito and A. J. Ikushima, "Absorption edge in silica glass," Phys. Rev. B, 62, P. 8584, 2000.

9. D.C. Hicks et al., "Dissociation of Liquid Silica at High Pressures and Temperatures," Phys. Rev. Lett., 97, $025502,2006$.

10. P. Temple et al., "Carbon dioxide laser polishing of fused silica surfaces for increased laser-damage resistance at 1064nm," Applied Optics, 21, 3249, 1982.

11. J. Horbach and W. Kob, "Static and dynamic properties of a viscous silica melt," Phys. Rev. B, 60, p. 3169, 1999.

12. D.P. Hand and P.S.J. Russel, "Solitary thermal shock waves and optical damage in optical fibers," Opt. Lett. Vol. 13, no. 9, p. 767, 1988.

13. Y. Shunto et al., "Evaluation of High-Temperature Absorption Coefficients in Optical Fibers," IEEE Phot. Tech. Lett., 16, p. $1008,2004$. 